\title{
Murine germ cell-specific disruption of Ift172 causes defects in spermiogenesis and male fertility
}

\author{
Shiyang Zhang ${ }^{1,2, *}$, Yunhao Liu'1,3,*, Qian Huang ${ }^{1,2}$, Shuo Yuan ${ }^{1,2}$, Hong Liu ${ }^{1,2}$, Lin Shi, \\ Yi Tian Yap ${ }^{2}$, Wei Li ${ }^{2}$, Jingkai Zhen ${ }^{1}$, Ling Zhang ${ }^{1,3}$, Rex A Hess ${ }^{4}$ and Zhibing Zhang ${ }^{2,5}$ \\ ${ }^{1}$ School of Public Health, Wuhan University of Science and Technology, Wuhan, Hubei, China, ${ }^{2}$ Department of \\ Physiology, Wayne State University, Detroit, Michigan, USA, ${ }^{3}$ Hubei Province Key Laboratory of Occupational \\ Hazard Identification and Control, Wuhan University of Science and Technology, Wuhan, Hubei, China, \\ ${ }^{4}$ Department of Comparative Biosciences, College of Veterinary Medicine, University of Illinois, Urbana, Illinois, \\ USA and ${ }^{5}$ Department of Obstetrics and Gynecology, Wayne State University, Detroit, Michigan, USA
}

Correspondence should be addressed to Z Zhang; Email: gn6075@wayne.edu

*(S Zhang and Y Liu contributed equally to this work)

\begin{abstract}
Intraflagellar transport (IFT) is a conserved mechanism essential for the assembly and maintenance of most eukaryotic cilia and flagella. IFT172 is a component of the IFT complex. Global disruption of mouse Ift172 gene caused typical phenotypes of ciliopathy. Mouse Ift172 gene appears to translate two major proteins; the full-length protein is highly expressed in the tissues enriched in cilia and the smaller $130 \mathrm{kDa}$ one is only abundant in the testis. In male germ cells, IFT172 is highly expressed in the manchette of elongating spermatids. A germ cell-specific Ift172 mutant mice were generated, and the mutant mice did not show gross abnormalities. There was no difference in testis/body weight between the control and mutant mice, but more than half of the adult homozygous mutant males were infertile and associated with abnormally developed germ cells in the spermiogenesis phase. The cauda epididymides in mutant mice contained less developed sperm that showed significantly reduced motility, and these sperm had multiple defects in ultrastructure and bent tails. In the mutant mice, testicular expression levels of some IFT components, including IFT20, IFT27, IFT74, IFT81 and IFT140, and a central apparatus protein SPAG16L were not changed. However, expression levels of ODF2, a component of the outer dense fiber, and AKAP4, a component of fibrous sheath, and two IFT components IFT25 and IFT57 were dramatically reduced. Our findings demonstrate that IFT172 is essential for normal male fertility and spermiogenesis in mice, probably by modulating specific IFT proteins and transporting/assembling unique accessory structural proteins into spermatozoa.

Reproduction (2020) 159 409-421
\end{abstract}

\section{Introduction}

Cilia and flagella are microtubule-based cellular appendages and play essential roles in mediating cell motility and/or sensing and transducing environmental stimuli (Carvalho-Santos et al. 2011, Ishikawa \& Marshall 2011). Intraflagellar transport (IFT) machinery, which was originally described in Chlamydomonas reinhardtii, is a motor-driven cargo trafficking system and is required for formation and maintenance of ciliary/ flagellar integrity and functions (Kozminski et al. 1993, Ishikawa \& Marshall 2011). IFT involves bidirectional transport of granule-like large protein complexes, named IFT particles, along the axoneme of cilia and flagella (Kozminski et al. 1993). IFT is responsible for anterograde transport of essential precursor proteins from the basal body to the assembly site at the axonemal tip and retrograde transport of turnover products back to the cell body. Kinesin-2 and cytoplasmic dynein-2 motor proteins regulate anterograde and retrograde trafficking in the IFT system, respectively (Cole et al. 1998, Pazour et al. 1999, Porter et al. 1999, Pedersen et al. 2006, Scholey 2013, Prevo et al. 2017).

Study of the composition of IFT particles isolated from $C$. reinhardtii found that they comprise of IFT-A and IFT-B complexes and are thought to mediate contacts between motors and axonemal precursor/ turnover proteins (Piperno \& Mead 1997, Cole et al. 1998, Ishikawa \& Marshall 2011). The IFT-A complex is composed of six proteins, while the IFT-B complex contains 16 proteins (Prevo et al. 2017). The interaction between the different IFT subunits is mediated by proteinprotein binding domains such as tryptophan/aspartic acid repeats (WD40 repeats), coiled-coil domains, or tetratricopeptide repeats (TPRs) (Piperno \& Mead 1997, Cole et al. 1998, Prevo et al. 2017). Mutation in the subunit of the IFT-A or IFT-B complex impedes the structure and function of cilia and flagella and thus leads 
to ciliopathies with distinct phenotypes, such as retinal degeneration, obesity, skeletal abnormalities, and cystic kidney (Beales et al. 2007, Keady et al. 2011, Waters \& Beales 2011, Aldahmesh et al. 2014, Perrault et al. 2015, Schaefer et al. 2016).

IFT172 was originally shown to be a component of the IFT-B complex in C. reinhardtii and is not only enriched at the basal body but also present along the axoneme of cilia or flagella (Cole et al. 1998, Pedersen et al. 2005, Tsao \& Gorovsky 2008). Although it is not required for formation of the IFT-B complex core, IFT172 is indispensable for cilia or flagella function. In the temperature-sensitive $C$. reinhardtii fla 11 strain, a single point missense mutation in ift 172 caused a defect in flagellar assembly at a non-permissive temperature (Adams et al. 1982, Pedersen et al. 2005). Further analysis of fla 11 mutant flagella showed accumulation of subunits of the IFT-B complex and abnormalities in the anterograde-to-retrograde particle turnover at the distal end of flagella, suggesting that IFT172 is critical for regulation of anterograde-to-retrograde IFT transition at the tip of flagella (Iomini et al. 2001, Pedersen et al. 2005). IFT172 is also conserved in a range of organisms possessing cilia or flagella. Mutation in OSM-1, the IFT172 ortholog in Caenorhabditis elegans, resulted in shortened axonemes of amphid cilia and defective chemosensory responses (Perkins et al. 1986, Bell et al. 2006). Insertional mutagenesis screen of zebrafish identified ift 172 mutation as a cause of kidney cysts, presumably involving disruption of renal cilia biogenesis (Sun et al. 2004). This gene is also required for photoreceptor outer segment development in zebrafish embryos (Gross et al. 2005, Sukumaran \& Perkins 2009). Moreover, inactivation of IFT172 leads to a wide range of diseases associated with ciliary dysfunction in mammals. Germline disruption of mouse homologue of IFT172 (wimple) resulted in abnormal phenotypes, characteristic of defects in the hedgehog signaling pathway and embryonic lethality, suggesting that IFT172 is essential for embryonic development (Huangfu et al. 2003, Gorivodsky et al. 2009, Burnett et al. 2017). Wide tissue distribution of IFT172 and polydactyly and shortened limbs in conditional Ift172 knockout (KO) mice suggest that the protein is implicated in the proper tissue development (McClintock et al. 2008, Howard et al. 2010). More recent study also demonstrated that IFT172 deficiency was associated retinal degeneration (Gupta et al. 2018). In human, mutation of IFT172 has been associated with pituitary hypoplasia in childhood, Mainzer-Saldino syndrome, asphyxiating thoracic dystrophy, and Bardet-Biedl syndrome (Halbritter et al. 2013, Lucas-Herald et al. 2015, Schaefer et al. 2016).

Although IFT172 contributes to the assembly and function of cilia and flagella in somatic cells, it is unclear whether it plays a role in the formation of mammalian sperm tail. IFT172 is highly expressed in testis and sperm possess a long flagellum (Howard \&
Maurer 2000), suggesting that it might be involved in the proliferation and development of male germ cells. In the present study, we investigated the function of IFT172 in spermatogenesis and male fertility. We found that mouse Ift172 gene translates two major proteins. The $130 \mathrm{kDa}$ protein is only expressed in male germ cells and is abundant in the manchette of elongating spermatids, while the full-length protein is likely to be expressed in both somatic cells and germ cells in the testis. Male germ cell-specific knockout of Ift 172 resulted in significantly decreased sperm count and motility, which were the causative factors for reduced male infertility. Sperm that completed spermatogenesis displayed aberrant sperm morphology, including bent tails. The levels of two major sperm cytoskeletal proteins ODF2 and AKAP4 were largely decreased in the mutant mice. However, inactivation of Ift172 had no effect on the testicular expression of most selected proteins of the IFT-B complex, except IFT25 and IFT57. This study demonstrates that IFT172 is essential for normal sperm function, probably through the transport of a set of unique cytoskeletal proteins for assembling into the sperm flagellum.

\section{Materials and methods}

\section{Ethics statement}

All animal research was approved by Wayne State University Institutional Animal Care and Use Program Advisory Committee (Protocol number: IACUC-18-02-0534).

\section{Generation of Ift172 conditional knockout (cKO) mice}

Ift $172^{\text {flox/flox }}$ mice (exons 2, 3 were floxed) were purchased from the Mutant Mouse Resource and Research CenterUniversity of North Carolina (MMRRC Strain ID: 32829), and Stra8-iCre mice were purchased from the Jackson Laboratory (Stock No:008208). Cre recombinase is only active in male germ cells (Sadate-Ngatchou et al. 2008). To generate the germ cell-specific Ift172 KO (cKO) mouse model, 3-4-monthold Stra8-cre males were crossed with 3-4-month-old Ift $172^{\text {flox/flox }}$ females to obtain Stra8-iCre; Ift $172^{\text {flox/++}}$ mice. The 3-4-month-old Stra8-iCre; Ift 172 flox/+ males were crossed back with 3-4-month-old Ift $172^{\text {flox/flox }}$ females again, and the Stra8-iCre; Ift 172 flox/flox were considered to be the homozygous cKO mice, and Stra8-iCre; Ift $172^{\text {flox/+ }}$ mice were used as the controls. Genomic DNA was isolated and used for genotyping the offspring as described previously (Zhang et al. 2018). The following primers were used for genotyping: Stra8-iCre forward: 5'-GTGCAAGCTGAACAACAGGA-3'; Stra8-iCre reverse: 5'-AGGGACACAGCATTGGAGTC-3', and Ift172 genotypes were determined as described previously (Howard et al. 2010).

\section{RT-PCR and Real-time PCR}

Total testicular RNA was isolated from the control and conditional Ift172 KO mice with TRIzol (Invitrogen). The 
RNA was reversely transcribed, and CDNAs were used for RT-PCR or real-time PCR. For RT-PCR, two sets of primers were used. Two RT-PCRs shared the same forward primer that is located in exon 1 (5'-GGAGTTGTCTCGGTCAGTGAG-3'). One reverse primer is located in the floxed exon 3 (5'-GTAGACATAGATGATGTTGTC- $\left.3^{\prime}\right)$; the other reverse primer is in exon 4 (5'-GATGAACTTGTTGCAGATGAC- $\left.3^{\prime}\right)$. Real-time PCRs were performed using $2 \times$ SYBR Green master mix (Bio-Rad). The primer set for Real-time PCR was designed with GeneScript tools (forward primer: 5'-TGCCCTGGACCATTCAGATT-3' located in exon 45, and reverse primer: $5^{\prime}$-CCAGTCTCGGACCTCTTCTC-3' located in exon 46). The primer set amplifying exon 1 to exon 3 (the same as RT-PCR as described previously) was also used for real-time PCR. 18S rRNA level was used to normalize expression level of target genes (Silva et al. 2009).

\section{Western blot analysis}

Tissue samples were collected from 3-4 month-old mice, and Western blot was conducted as previously described (Zhang et al. 2016). The following antibodies were used: anti-AKAP4 (1:4000, from Dr George L Gerton at University of Pennsylvania); anti-ODF2 (1:800, Cat No: 120581AP, Proteintech); anti-IFT81 (1:2000, Cat No: 11744-1AP, Proteintech); anti-SPAG16L (1:1000, generated in our laboratory); $\beta$-actin (1:2000, Cat No: 4967S, Cell Signaling); and GAPDH (1:500, Cat No: SC-47724, Santa Cruz). Antibodies against IFT20, IFT25, IFT27, IFT57, and IFT140 (1:2000) were provided by Dr Pazour's laboratory at University of Massachusetts Medical School. Four commercial antiIFT172 antibodies were used: LifeSpan BioSciences (Cat No: LS-B8206); Santa Cruz Biotechnology (A-11: sc398393, 1:1000); ThermoFisher Scientific (Cat Nos: pA5-43702 and pA5-25305. 1:1000 for both); and one fromDr Kinga $M$ Bujakowska at Harvard University (1:1000) (Gupta et al. 2018).

\section{Spermatozoa counting}

Sperm cells were collected from cauda epididymides in warm PBS solution and fixed for $10 \mathrm{~min}$ at room temperature with $2 \%$ formaldehyde. Counts were made using a hemocytometer chamber under a light microscope, and sperm number was calculated by standard methods (Zhang et al. 2006).

\section{Spermatozoa motility assay}

Sperm were collected after swimming out from the cauda epididymides in warm PBS. Sperm motility was observed using an inverted microscope (Nikon) equipped with $10 \times$ objective. Movies were recorded at 15 frames/s with a SANYO (Osaka, Japan) color charge-coupled device, high-resolution camera (VCC-3972), and Pinnacle Studio HD (version 14.0) software. For each sperm sample, ten fields were analyzed. Individual spermatozoa were tracked using Image J (National Institutes of Health, Bethesda, MD) and the plug-in MTrackJ. Sperm motility was calculated as curvilinear velocity $(\mathrm{VCL})$, which is equivalent to the curvilinear distance (DCL) traveled by each individual spermatozoon in $1 \mathrm{~s}(\mathrm{VCL}=\mathrm{DCL} / \mathrm{t})$.

\section{Histology on tissue sections}

Testes and epididymides of adult mice were fixed in $4 \%$ formaldehyde and PBS solution, paraffin embedded, and sectioned for histology into $5 \mu \mathrm{m}$. Sections were stained with hematoxylin and eosin and examined using a BX51 Olympus microscope and photographed with a ProgRes C14 camera (Jenoptik Laser, Germany).

\section{Isolation of spermatogenic cells and epididymal sperm for immunofluorescence analysis}

Spermatogenic cells were prepared as previously described (Zhang et al. 2016). Briefly, testes from an adult WT mouse were decapsulated and placed in $5 \mathrm{~mL}$ DMEM containing $0.5 \mathrm{mg} / \mathrm{mL}$ collagenase IV (Sigma-Aldrich) and $1.0 \mathrm{mg} / \mathrm{mL}$ DNase I (SigmaAldrich), and was incubated for $30 \mathrm{~min}$ at $32^{\circ} \mathrm{C}$ to dissociate testicular cells, then centrifuged for $5 \mathrm{~min}$ at $200 \mathrm{~g}$. Dispersed mixed testicular cells were fixed by 15 min incubation in $4 \%$ paraformaldehyde/PBS (containing 4\% sucrose) at room temperature, then washed three times with PBS. Prior to plating, cells were re-suspended in PBS and $100 \mu \mathrm{L}$ of cell suspension was spread on SuperFrost/Plus microscope slides (Fisher Scientific) and allowed to air-dry. For immunofluorescence staining, anti-IFT172 antibodies (1:100, Cat No: LS-B8206, LifeSpan BioSciences; 1:100 from Dr Kinga M Bujakowska; or ThermoFisher Scientific (1:100, Cat No: pA5-25305) and other primary antibodies were used, including anti- $\alpha$-tubulin antibody (1:200, Cat No: T9026, Sigma) and anti-Sp56 antibody (1:200, Cat No: sc-373726, Santa Cruz Biotechnology). Images were captured by confocal laser-scanning microscopy (Zeiss LSM 700). For immunofluorescence on sperm samples, sperm were obtained from cauda epididymis of control and conditional Ift172 knockout mice, centrifuged at $3000 \mathrm{~g}$, washed and resuspended in PBS, and layered onto polylysine-coated slides. The preparations were fixed with $4 \%$ paraformaldehyde and permeabilized with $0.1 \%$ Triton X-100. The rest of the procedure was the same as described in the testicular cell staining.

\section{Immunofluorescence analysis on testis sections}

Fresh testes from control and conditional Ift172 KO mice were fixed with $4 \%$ paraformaldehyde in $0.1 \mathrm{M} \mathrm{PBS}(\mathrm{pH} 7.4)$ and $5 \mu \mathrm{m}$ paraffin sections were made. For the immunofluorescence, the method described by Tsuneoka was used (Tsuneoka et al. 2006). Briefly, the sections were incubated with an anti-IFT172 antibody (1:100, pA5-25305, ThermoFisher Scientific) at $4^{\circ} \mathrm{C}$ overnight. Slides were washed with PBS and incubated for $1 \mathrm{~h}$ at room temperature with Cy3-conjugated anti-rabbit IgG secondary antibody (1:5000; Jackson ImmunoResearch Laboratories). Following secondary antibody incubation, the slides were washed with PBS three times, mounted using VectaMount with DAPI (Vector Laboratories, Burlingame, CA), and sealed with a cover slip. Images were captured by a confocal microscopy at the Wayne State University Microscopy Core facility.

\section{Transmission electron microscopy}

Mouse testes and epididymal sperm were fixed with $3 \%$ glutaraldehyde and $1 \%$ paraformaldehyde in $0.1 \mathrm{M}$ sodium 
cacodylate, $\mathrm{pH} 7.4$, at $4^{\circ} \mathrm{C}$ overnight, and processed for electron microscopy as reported (Zhang et al. 2016). Images were taken with a Jeol JEM-1230 transmission electron microscope at Virginia Commonwealth University.

\section{Results}

\section{Mouse Ift172 gene translates two major proteins}

To examine mouse IFT172 tissues distribution, Western blots were conducted using multiple commercial anti-IFT172 antibodies. Among the four commercial anti-IFT172 antibodies used, only the antibody from ThermoFisher Scientific (pA5-25305) detected the protein at the predicted size in the mouse tissues examined. The full length IFT172 was highly expressed in the testis and was also detected in the brain, lung, and liver. Besides the full length IFT172, the antibody also detected a $130 \mathrm{kDa}$ protein only in testis (Fig. 1A). In addition, some smaller proteins were also detected in the examined tissues and these may represent nonspecific binding using the antibody. The antibody was further used to examine IFT172 expression in the mouse testes collected during the first wave of spermatogenesis. The full length IFT172 protein was detected at a similar level throughout the whole spermatogenesis process. However, the $130 \mathrm{kDa}$ protein was not detected until day 12 after birth and then was present throughout the experimental period (Fig. 1B). The two IFT172 proteins were also detected using another anti-IFT172 antibody generated recently by $\mathrm{Dr}$ Kinga $M$ Bujakowska at Harvard University (Supplementary Fig. 1, see section on supplementary materials given at the end of this article).

\section{Localization of IFT172 in male germ cells}

Immunofluorescence staining was conducted to determine localization of IFT172 in isolated male germ cells. Three different anti-IFT172 antibodies were used. Strong IFT172 signal was detected in the elongating spermatids from these antibodies, and the signal was co-localized with a marker of the manchette, $\alpha$-tubulin, indicating that IFT172 is a component of the manchette (Fig. 2).

\section{Generation of male germ cell-specific Ift172 cKO mice}

To study the role of IFT172 in spermatogenesis, the Cre/lox $P$ system was used to generate male germ cellspecific Ift172 cKO mice as described previously (Howard et al. 2010, Zhang et al. 2016, Liu et al. 2017) (Supplementary Fig. 2). Disruption of Ift172 gene was first evaluated by RT-PCR and Real-time PCR using the primers as illustrated in Supplementary Fig. 3A. When the primer set that amplified exons 1 to 3 was used, a strong 321-bp PCR product was observed only in the control mouse as predicted, and only a trace amount of
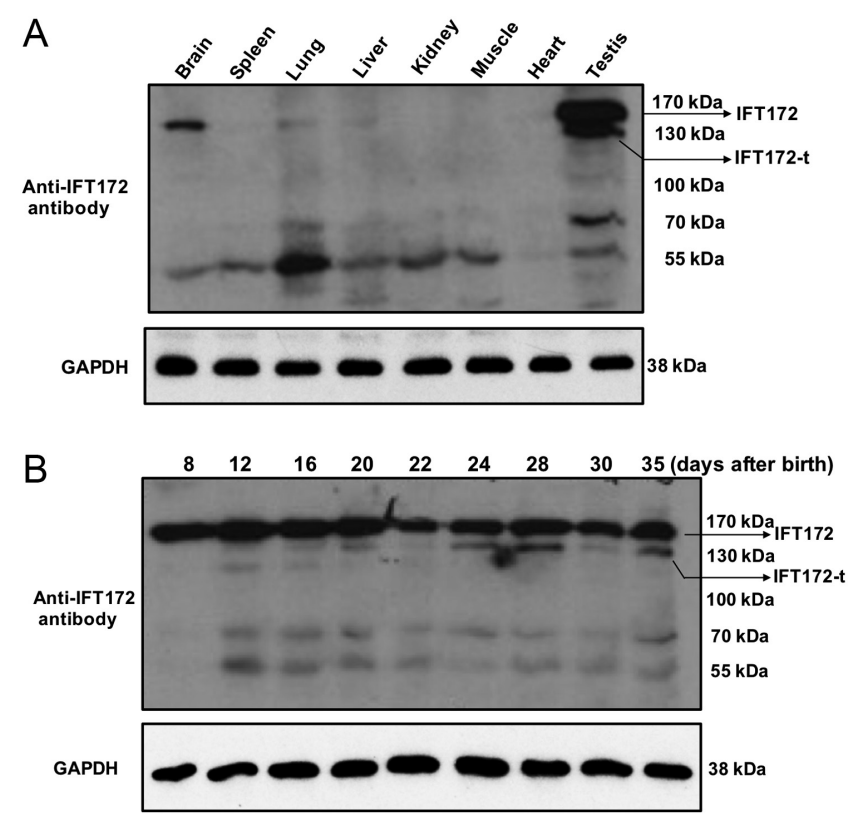

Figure 1 IFT172 tissue distribution and testicular expression during the first wave of spermatogenesis examined by Western blot analysis. Four commercial IFT172 antibodies were used and only the one from ThermoFisher Scientific (pA5-25305) cross-reacted with the protein corresponding to the full-length mouse IFT172 protein. (A) Expression of IFT172 in multiple mouse tissues extracts. The full length IFT172 was detected in the testis, brain, lung, and liver. In addition to the full length IFT172 protein, a 130 kDa protein was also detected only in the testis. Some smaller proteins were also detected in all tissues examined and these may represent nonspecific binding using the antibody. (B) Dynamic expression of IFT172 during the first wave of spermatogenesis. The full length IFT172 was expressed at a similar level throughout the whole process. However, the 130 KDa protein was not expressed until day 12 after birth, when germ cells became the predominant cell population in the testis; and the level appeared to be increased after day 24, when spermiogenesis occurred.

PCR product was detected in the cKO mouse. When the primer set that amplified exons 1 to 4 was used, a PCR product as predicted size (372 bps) was observed in the control mouse; however, in the $\mathrm{CKO}$ mouse, the signal of the same PCR product was dramatically reduced; instead, a smaller PCR product (about 115 bps) was amplified (Supplementary Fig. 3B). To compare testicular Ift172 mRNA expression levels between control and Ift172 cKO mice, real-time PCR was conducted using two primer sets. The first set was the same as the RT-PCR primer set that amplified exons 1 to 3, and the second set was to amplify the region closed to the $3^{\prime}$ end of Ift172 cDNA. Results from both sets demonstrated that testicular Ift172 mRNA expression level was significantly reduced in the $\mathrm{CKO}$ (Supplementary Fig. 3C).

Germ-cell specific disruption of Ift172 was further confirmed by Western blot analysis. Both the full-length and the $130 \mathrm{kDa}$ IFT172 proteins were present in the control mice. Either none or only trace amounts of the $130 \mathrm{kDa}$ protein was detected in the conditional Ift172 $\mathrm{KO}$ mice, and the full length IFT172 level was also 

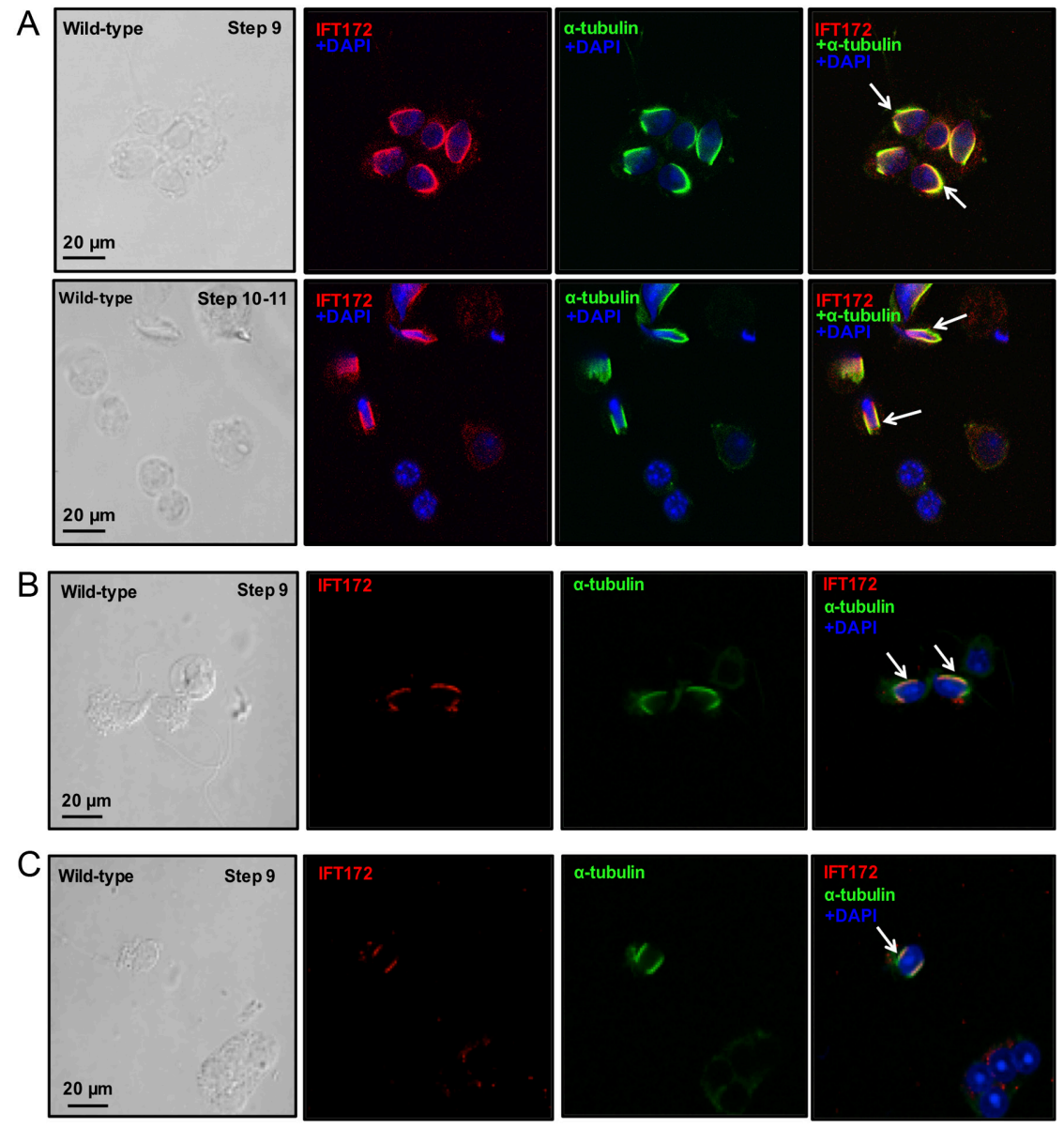

reduced in the conditional Ift172 $\mathrm{KO}$ mice (Fig. 3A). Immunofluorescence staining was also conducted on the isolated testicular cells. Strong IFT172 signal was detected in the manchette of isolated male germ cells from the control mice, whereas the signal was greatly diminished in the mutant mice (Fig. 3B).

Disruption of Ift172 in germ cells was also examined on testicular sections. Using the same antibody as the one used for Western blot analysis (ThermoFisher Scientific, Cat No: pA5-25305), specific IFT172 signal was detected in the manchette of elongating spermatids of control mice, but the signal was missing in the elongating spermatids of conditional Ift172 $\mathrm{KO}$ mice (Supplementary Fig. 4). All other commercial anti-IFT172 antibodies tested did not result in any specific signal.

\section{Knockout of Ift172 specifically in male germ cells results in reduced male fertility}

Homozygous Ift172-deficient mice survived to adulthood and did not exhibit any gross abnormalities in the ratio of testis weight to body weight (Table 1 ). To examine the effect of disruption of Ift172 gene on male fertility, Ift 172 mutant or control mature males were mated with 3 to 4 months old WT female mice for over 2 months. All ten control males displayed normal fertility and produced normal-sized litters. However, less than 50\% of the conditional Ift172 KO mice were fertile and they produced offspring with reduced litter sizes (Table 1).

\section{Disruption of Ift172 results in aberrant sperm morphology, reduced sperm counts and motility}

To determine the causative factors of male infertility, morphology of cauda epididymal sperm was examined by light microscopy. Sperm density in the control mice was significantly higher than those observed in the Ift 172 cKO mice under the same dilution, as examined by light microscopy (Supplementary Fig. 5). Under high magnification, most spermatozoa from the Ift $172 \mathrm{cKO}$ mice displayed bent tails. Vacuoles were present in the flagella of some mutant sperm (Fig. 4A). These abnormal sperm made up about $80 \%$ of the total sperm. Ift 172 disruption also resulted in a reduction in sperm counts and sperm motility, compared to the control mice (Fig. 4B and C).

\section{Inactivation of Ift172 leads to spermatogenesis defect}

Aberrant sperm morphology and reduced sperm counts and motility may be caused by spermatogenesis defects. Thus, testicular histology was examined in control 

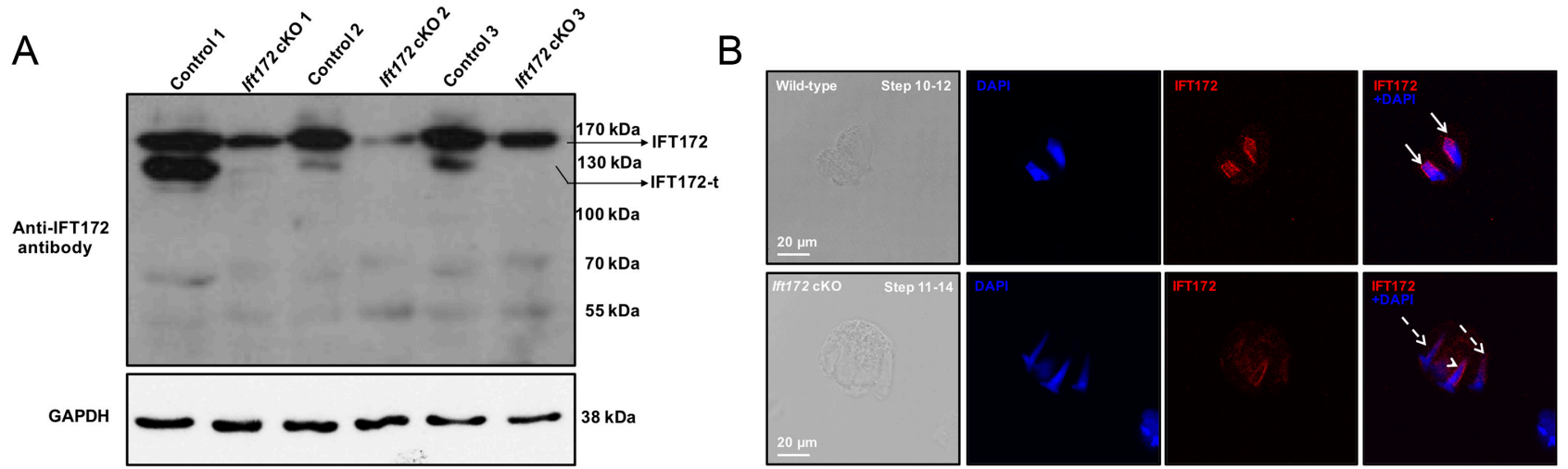

Figure 3 IFT172 protein expression is dramatically reduced in the germ cells of conditional Ift172 KO mice. (A) Examination of testicular IFT172 expression in the control and conditional Ift $172 \mathrm{KO}$ mice by Western blot analysis. Notice that the full length IFT172 was still present in the conditional Ift172 KO mice but the level was reduced; however, no or only trace amount of the $130 \mathrm{kDa}$ protein was detected in the cKO mice. (B) Examination of IFT172 expression in germ cells by immunofluorescence staining. Isolated germ cells were stained with the IFT172 antibody (red). IFT172 signal was observed in the manchette (arrows) of elongating spermatids from the control mice, but it was almost absent in the Ift172 CKO mice (dashed arrows). Remaining IFT172 signal was detected in some cells of the Ift172 cKO mice (arrowhead). The nuclei were stained in blue (DAPI).

and Ift172 cKO mice. H\&E staining revealed that all stages of spermatogenesis in the control mice were present, and spermatozoa were found to be present in the lumen of the seminiferous tubules (Fig. 5A, upper panels). However, spermatogenesis was affected in the spermiogenesis phase in Ift172 cKO mice, with fewer sperm tails being observed in the lumen of seminiferous tubules (Fig. 5A, lower panels). Histological evaluation of the cauda epididymides revealed well-developed sperm and normal sperm concentrations in the control mice (Fig. 5B, upper panels), but in Ift172 cKO mice, fewer sperm were present in the lumen and round bodies and cytoplasmic debris were also present (Fig. 5B, lower panels).

\section{Abnormally developed manchette and centrosomes, but normal acrosome biogenesis in Ift172-deficient germ cells}

Given that IFT172 is present in the manchette of elongating spermatids, we examined the effect of the depletion of IFT172 on manchette formation. Immunofluroescence staining was conducted on isolated testicular germ cells using an anti- $\alpha$-tubulin antibody that labels the manchette. The signals were present in both the control and cKO mice. However, the manchette length in the cKO mice appeared to be longer than that in the control (Fig. 6A).
Basal bodies/centrosomes are the template for cilia formation (Ishikawa \& Marshall 2011). It has been proposed that the centrosome may function as the nucleation site for initiation of the manchette (Lehti \& Sironen 2016). Therefore, an immunofluorescence study was conducted to determine whether disruption of Ift 172 could affect the formation of centrosomes in male germ cells. In control mice, IFT172 was detected in the manchette of elongating spermatids and a dot-like fluorescence signal for $\gamma$-tubulin, a centrosome marker, was detected in the caudal region of the spermatid nucleus. However, multiple centrosomal signals were observed in about $22.5 \%$ of the Ift 172-null male germ cells (Fig. 6B) and the number was less than $1 \%$ in the control mice.

Anti-Sp56 antibody was also used to evaluate the effect of Ift172 disruption on the formation of the acrosome. Sp56 was present in the acrosomal region of round spermatids in both the conditional Ift172 $\mathrm{KO}$ and control mice. However, in the elongating spermatids of Ift172 cKO mice, Sp56 showed abnormal aggregation in some cells (Fig. 6C).

\section{Ultrastructural defects in the testis and epididymal sperm of conditional Ift172 KO mice}

Transmission electron microscopy (TEM) was performed to study the impact of Ift172 disruption on germ cell ultrastructure (Fig. 7A) and epididymal sperm (Fig. 7B).

Table 1 Fertility, fecundity and testis weight of control and lft172 mutant mice.

\begin{tabular}{lcccc}
\hline Genotype & Male fertility & Litter size & Testis/body weight $(n=10, \mathrm{mg} / \mathrm{g})$ & Control/HO testis weight $(n=10)$ \\
\hline Control & $10 / 10$ & $8.67 \pm 1.2(n=10)$ & $8.56 \pm 0.34$ & $1.09 \pm 0.11$ \\
$\mathrm{HO}$ & $6 / 13$ & $4.57 \pm 2.5(n=6)$ & $8.32 \pm 0.46$ & \\
\hline
\end{tabular}

Sexually mature males were bred to WT females for at least two months. Litter size was recorded for each mating. Testis weight and body weight of adult mice were measured. 
A
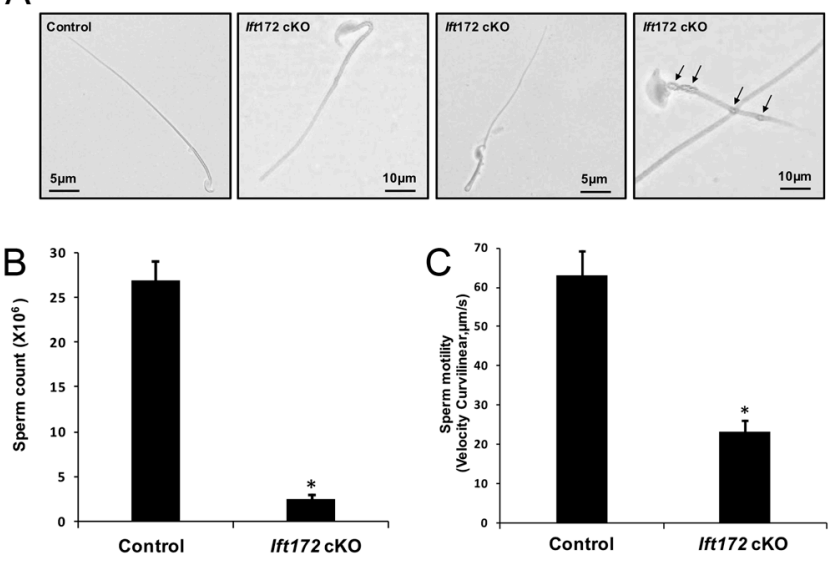

Figure 4 Knockout of Ift 172 results in aberrant sperm morphology with reduced sperm count and motility. (A) Morphological examination of epididymal sperm by light microscopy at high magnification. Most Ift172-null sperm displayed bent flagella at the midpiece. Vacuoles were present in the flagellum of some mutant sperm (arrows). (B) The number of sperm was significantly reduced in the Ift 172 cKO mice; ${ }^{*} P<0.05$; (C) Sperm motility measured as curvilinear velocity $(\mathrm{VCL})$ was significantly decreased in the Ift172 cKO mice, compared to the control. ${ }^{*} P<0.05$.
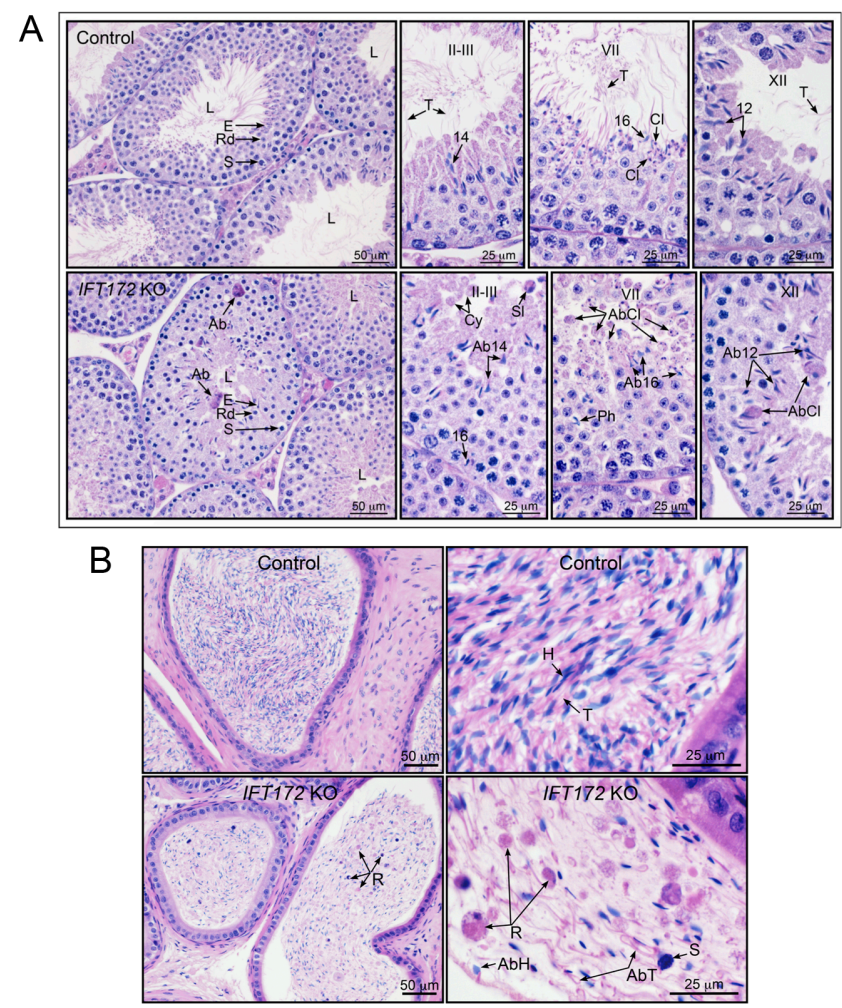

Figure 5 Histology of the testis and epididymis from the control and Ift172 KO mice. (A) Representative histology of the testis from the control and conditional Ift172 KO mouse. Upper panels: Low and high magnifications of the testis from control mouse. At low magnification, seminiferous tubules show wide lumens (L) with elongated spermatid (E) tails. The seminiferous epithelium contains normal layers of germ cells: spermatocytes $(\mathrm{S})$, round spermatids $(\mathrm{Rd})$, and elongated
In control mice, germ cells developed normally. Wellorganized manchettes were observed and properly shaped nuclei and acrosomes were present (Fig. 7A, a). However, in the Ift172 cKO mice, the manchette was formed, but appeared to be longer and mislocalized. The acrosome appeared to be normal in round spermatids, but elongating spermatids with abnormally developed heads also showed distorted acrosomes (Fig. 7A, b-f). A normal ' $9+2$ ' central microtubule axonemal complex and accessory structures were observed in the epididymal sperm of the control mice (Fig. 7B, a and b). However, some sperm of Ift172 cKO mice displayed abnormal core axonemes and accessory structures, including missing or disorganized ' $9+2$ ' arrangement of the microtubules, missing outer dense fibers (ODFs). Failure of mitochondria and ODFs to assemble properly into the flagellum was also detected (Fig. 7B, c-j). The fibrous sheath structure seemed to be normal in the lft $172 \mathrm{cKO}$ mice.

\section{Effect of IFT172 disruption on expression of sperm structural proteins and other IFT proteins}

The impact of IFT172 inactivation on expression of components of the sperm flagellum was explored by

spermatids (E). At higher magnification, specific stages of spermatogenesis are shown. In stages II-III, tails of step 14 spermatids are seen extending into the lumen. In late stage VII, step 16 spermatid heads line the lumen with their long tails $(\mathrm{T})$ extending into the lumen. Cytoplasmic lobes $(\mathrm{Cl})$, which later form residual bodies to be phagocytized by Sertoli cells, are seen forming near the heads of step 16 spermatids. At stage XII, step 12 spermatids have long tails (T) extending into the lumen. Lower panels: Low and high magnifications of the testis from IFT172 cKO mouse. At low magnification, seminiferous tubules show lumens (L) that are very small and contain few spermatid tails. Spermatogenesis appears normal until the formation of elongated spermatids (E), with normal layers spermatocytes (S) and round spermatids (Rd). In some tubules, abnormal spermatids with attached cytoplasm are found in the epithelium (Ab). At higher magnification, specific stages of spermatogenesis are shown. In stages II-III, abnormal step 14 spermatid heads are present in the seminiferous epithelium, but tails are not observed extending into the lumen. Sloughed abnormal spermatids with attached cytoplasm (SI) and round cytoplasmic bodies (Cy) are found in the lumen. The head of a step 16 spermatid is seen near the basement membrane where it has been phagocytized by the Sertoli cell. In late stage VII, round bodies of abnormal cytoplasmic lobes $(\mathrm{AbCl})$ are seen extending into the lumen. Abnormal spermatid 16 heads are also identified, as well as phagocytized (Ph) step 16 spermatid heads. At stage XII, abnormal step 12 spermatids are seen in the epithelium, along with abnormal cytoplasmic lobes attached to the spermatids $(\mathrm{AbCl})$. (B) Representative histology of the epididymis from the control and conditional Ift $172 \mathrm{KO}$ mouse. Upper panels: Cauda epididymis from control mouse showing highly concentrated sperm, with alignment of sperm heads $(\mathrm{H})$ and tails (T). Normal sperm heads and long attached tails are highly compacted in the lumen. Lower panel: Cauda epididymis from Ift172 cKO mouse showing a low concentration of sperm in the lumen, with non-aligned sperm and numerous abnormalities. Abnormal sperm heads $(\mathrm{AbH})$ and tails (AbT) are present, along with sloughed round bodies of residual spermatid cytoplasm (R). An occasional sloughed spermatocyte nucleus (S) was observed. 


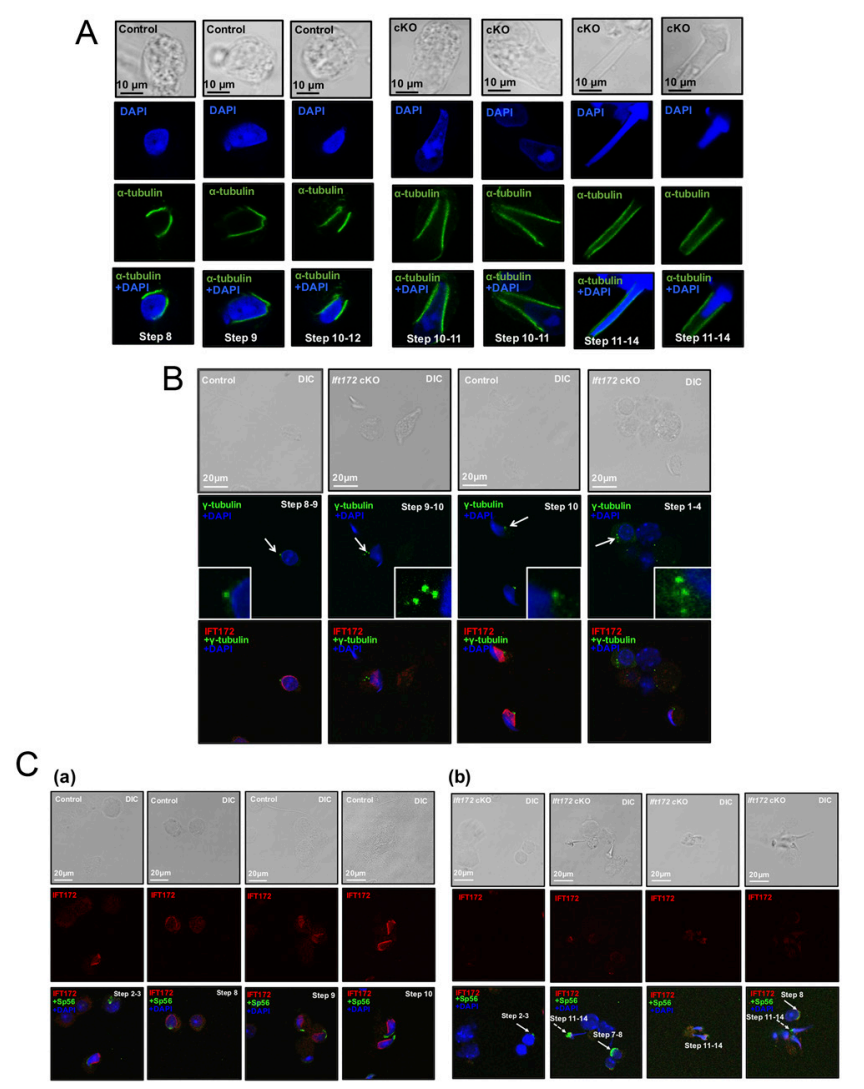

Figure 6 Knockout of Ift 172 leads to abnormal manchette morphology and centrosomes but normal acrosome biogenesis in germ cells. Isolated germ cells from control mice and conditional Ift172 KO mice were stained with indicated antibodies. (A) IF was conducted with an anti- $\alpha$-tubulin antibody that labeled manchette of elongating spermatids (in green). Nuclei were stained in blue (DAPI). Notice that the manchette of cKO mice (right panel) appeared to be longer than that in the control mice (left panel); (B) IF was conducted with the IFT172 antibody (in red) and a centrosome marker, $\gamma$-tubulin (in green). Notice that multiple centrosome signals were discovered in the Ift $172 \mathrm{cKO}$ male germ cells (white arrows). (C) IF was conducted on germ cells isolated from the control (a) and Ift $172 \mathrm{cKO}$ mice (b) with the anti-IFT172 antibody (in red) and an acrosome marker, Sp56 (in green). Notice that Sp56 localization was normal in round spermatids (white arrows), but appeared to be abnormal in some elongating spermatids in the Ift $172 \mathrm{cKO}$ mice (white dashed arrows).

Western blotting and immunofluorescence staining analysis. The testicular expression levels of both ODF2 (outer dense fiber protein 2), a major component of outer dense fibers of sperm flagella (Donkor et al. 2004), and AKAP4 (A-kinase anchoring protein 4), a scaffold protein required for the formation of the fibrous sheath (Miki et al. 2002), was significantly reduced in the conditional Ift172 KO mice, compared to the control mice (Fig. 8A). Consistently, immunofluorescence staining showed that these two proteins were present in the sperm flagellum of the control mice, while their signals were dramatically reduced in the $1 \mathrm{ft} 172$ cKO mice (Fig. 8D, E and Supplementary Fig. 6). Expression levels of a central apparatus protein SPAG16L and three IFT proteins (IFT20, IFT27 and IFT81) were also examined by Western blotting. There was no significant difference in their expression levels between the control and mutant mice (Fig. 8A). We next examined expression of other IFT proteins, including IFT25, IFT57, IFT74, and IFT140. Only the expression levels of IFT25 and IFT57 were found to be significantly reduced in the CKO mice (Fig. 8B and C).

\section{Discussion}

Using two anti-IFT172 antibodies for Western blot analysis, we discovered two major cross-reacted proteins, one about $170 \mathrm{kDa}$ and the other one about $130 \mathrm{kDa}$. The former is likely the full-length mouse IFT172 protein. In the testis, this protein was expressed at a stable level during the first wave of spermatogenesis, and it was still expressed in the conditional KO mice; however, the level was reduced. Thus, the full-length IFT172 is likely expressed in both somatic cells and germ cells. Instead, the $130 \mathrm{kDa}$ protein was present only in the testis. Interestingly, this protein was not detected in the early phase of spermatogenesis, when germ cells are not the predominant cell population (Bellve et al. 1977). It was missing in the germ cell specific conditional $\mathrm{KO}$ mice. Thus, the $130 \mathrm{kDa}$ protein is likely a germ cell specific IFT172 protein. Given that both antibodies recognize the region near the $\mathrm{N}$-terminal end, it is likely the new isoform is generated through a germ cellspecific splicing mechanism in the C-terminus of the full length protein. Our laboratory is currently characterizing the new isoform. It is yet to be determined if the fulllength IFT172 is required for normal male fertility. Other transgenic Cre mice should be used to study the role of the full-length IFT172 in the somatic cells of the testis.

Data presented in this study demonstrated that IFT172 is involved in male germ cell development and male fertility. The number of sperm collected from the cauda epididymis of conditional Ift172 KO mice was significantly reduced, compared to the control mice. Although some Ift $172 \mathrm{CKO}$ sperm could progress through all phases of spermatogenesis, most of them displayed abnormal morphology and reduced motility. Histological analysis of testes from the mutant mice revealed all germ cell types, including spermatogonia, spermatocytes, round and elongating spermatids; however, very few mature spermatozoa with normal flagella were detected. Thus, inactivation of Ift172 appears to have no effect on mitosis and meiosis, but hinders spermiogenesis. These observations are consistent with the role of the IFT system in assembly and maintenance of flagella and cilia (Prevo et al. 2017). Although reduced sperm counts and motility would account for male infertility, about $40 \%$ of Ift 172 null male mice were fertile. Therefore, some normal spermatozoa are being released. The decreased male fertility could be explained by at least two possibilities. 

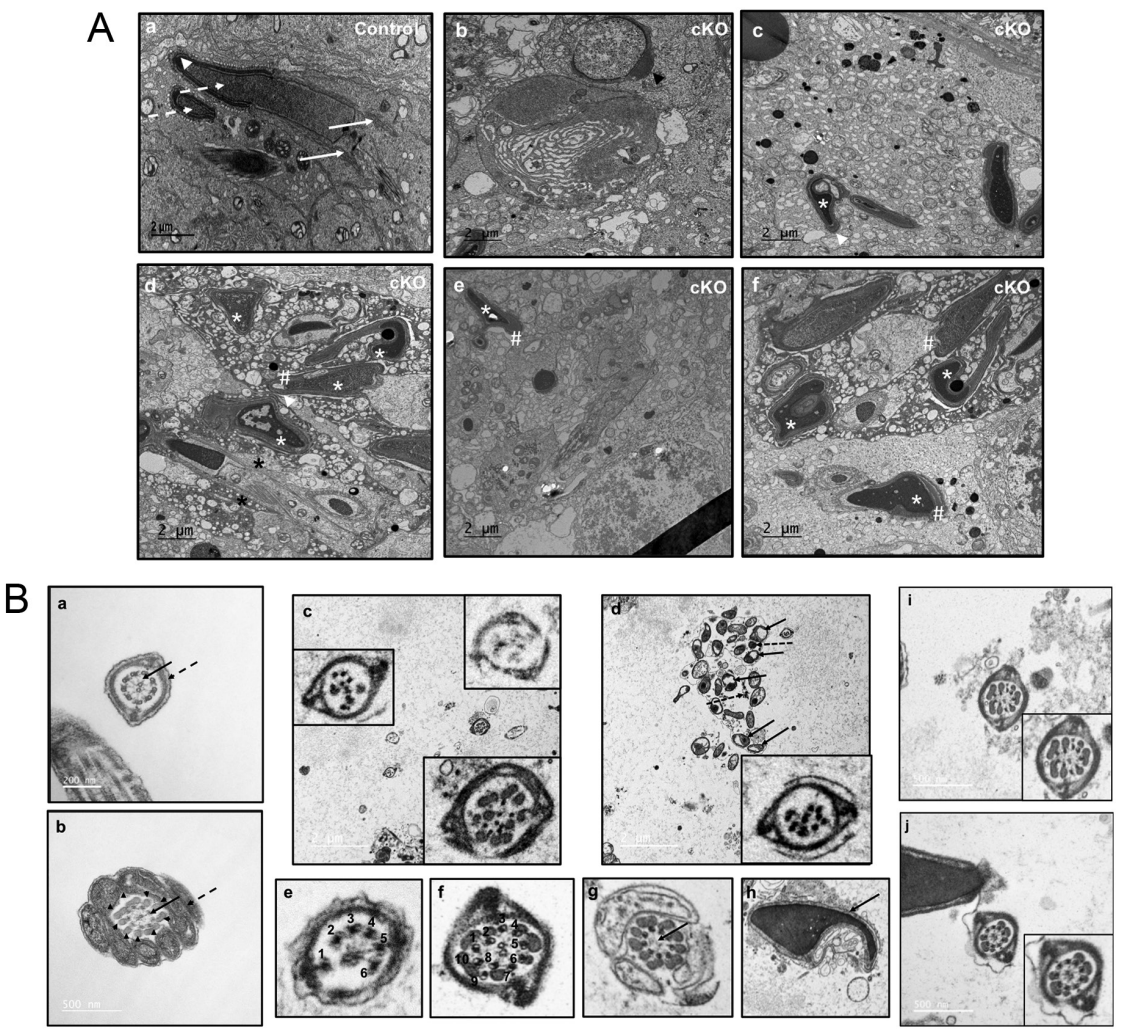

Figure 7 Analysis of testis and epididymal sperm of the control and Ift $172 \mathrm{cKO}$ mice by transmission electron microscopy (TEM). (A) Representative TEM images of testes from control (a) and conditional Ift172 KO mice (b-f). Normally formed manchette (arrows), heads (dashed arrows), and acrosome (arrow heads) were present in the control mice. However, in the cKO mice, a number of abnormalities were observed, including abnormal head formation (white * in $\mathrm{c}-\mathrm{f}$ ), mislocalized and longer manchette (black*). The acrosome was normal in the round spermatid (b), but distorted in elongating spermatids, probably secondary to the abnormal heads (\# in d-f). (B) Representative TEM images of epididymal sperm. Sperm from the control mice $(a, b)$ have normal ' $9+2$ ' axonemal microtubule cores (arrows) and accessary structures (dashed arrows and arrow heads). (c-j) TEM of sperm from the Ift $172 \mathrm{cKO}$ demonstrate multiple abnormalities in both the core axonemes and accessory structures. (c) The left and right lower inserts show two flagella with disrupted core structures; the right upper insert shows a flagellum with almost no internal structure. (d) The arrows point to mitochondria, and the dashed arrows point to disrupted unit fibers of the outer dense fiber (ODF) that are not assembled into the flagellum. The insert illustrates another flagellum with disrupted internal structure. (e) This image represents a flagellum with only six outer microtubules. (f) This photo shows a flagellum with ten outer microtubules. (g) In this cross section of the midpiece, the flagellum has normal mitochondria and ODF, as well as nine outer doublet microtubules in the axonemal complex, but the central apparatus (arrow) is missing the two microtubules and associated linking proteins. (h) This is the head of a spermatozoon (arrow) with an abnormal nuclear shape. (i) The flagellum shows a normal fibrous sheath, but a disorganized axonemal core structure. (j) The flagellum shows a normal fibrous sheath and core axoneme structure, but there is a reduction in the ODF subunits.

First, knockout of IFT172 was not complete in this mouse model, and thus the residual IFT172 may be sufficient for some germ cells to complete spermiogenesis. This is supported by the fact that the non-deleted RT-PCR product was still amplified in the cKO mice, and trace amounts of the $130 \mathrm{kDa}$ IFT172 protein was detected in some cKO mice by either Western blot analysis and immunofluorescence staining. Second, as the IFT system consists of at least 22 subunits (Prevo et al. 2017), other IFT proteins may partially compensate for the loss of function when IFT172 is inactivated.

Immunofluorescence staining on the isolated male germ cells revealed that IFT172 is exclusively located in the manchette of elongating spermatids, a unique and transient structure required for spermiogenesis (Hermo et al. 2010). The manchette plays a role in shaping the spermatid head and delivering proteins important for development of the functional sperm flagellum via an intra-manchette transport (IMT) system (Meistrich et al. 1990, Kierszenbaum 2002). It is believed that some cargo proteins are temporarily stored in the manchette and transported to the basal body of sperm by IMT and the developing sperm flagellum by IFT (Kierszenbaum 2002, Lehti \& Sironen 2016). The presence of IFT172 in the manchette suggests that the protein might be implicated in the process of IMT. However, the fact that sperm flagella were still made in the CKO mice indicates that IFT172 might not be a key regulator for core axoneme formation in the flagellum. Given that most Ift172-null sperm displayed bent flagella at the midpiece and vacuoles were present in the flagellum of some mutant sperm, it appears that IFT172 has a primary 

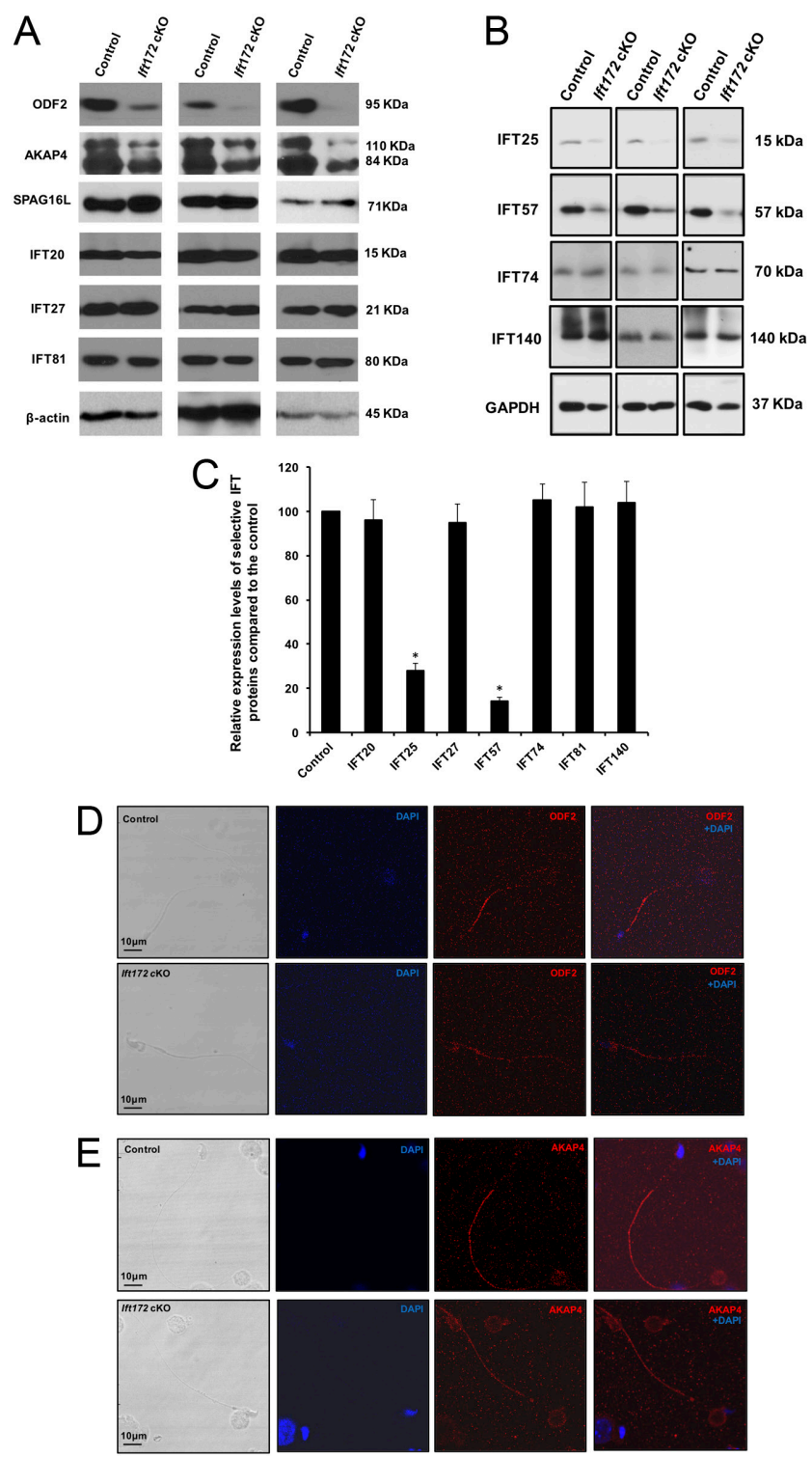

Figure 8 Expression of ODF2, AKAP4, SPAG16L, and selective IFT proteins in the conditional Ift172 KO mice. (A) Representative Western blotting images showing testicular expression levels of three major components of sperm tail (ODF2, AKAP4, and SPAG16L), and three subunits of the IFT system (IFT20, IFT27, and IFT81) using specific antibodies in three control and three conditional Ift172 KO mice. Disruption of Ift172 expression decreased the level of ODF2 and AKAP4, while it had little effect on the expression levels of SPAG16L and three IFT proteins. $\beta$-Actin was used as an internal control. (B) Representative Western blotting images of another four IFT proteins. Notice that expression levels of IFT25 and IFT57 in the cKO mice were lower than that in the control mice. (C) Statistical analysis of relative expression of the IFT proteins normalized by $\beta$-actin or GAPDH. There is no difference in expression levels of IFT20, IFT27, IFT74, IFT81, and IFT140 between the control and the Ift172 CKO mice. IFT25 and IFT57 expression levels are significantly reduced in the Ift172 cKO mice. (D and E) Representative images of localization of ODF2 and AKAP4 in the epididymis sperm of a control mouse and an Ift172 cKO mouse, respectively. Both ODF2 and AKAP4 signals were reduced in the Ift172-null sperm flagella. role in sperm accessory structure formation. Such cargo proteins might include ODF2 and AKAP4, whose signals were significantly reduced in the epididymal sperm of the Ift 172 cKO mice. Structural defects in the axoneme and reduced motility may be due to a reduction in accessory structures. Thus, different IFT components might play different roles for sperm flagella formation, which is supported by our recent finding that IFT74 is likely involved in core axoneme assembly (Shi et al. 2019). It has been reported that IFT172 is critical for the regulation of anterograde-to-retrograde IFT transition at the tip of C. reinhardtii flagella (lomini et al. 2001, Pedersen et al. 2005). Thus, it is likely that IFT172 directly participates in the formation of developing sperm tails. Disruption of Ift 172 gene in germ cells did not affect manchette formation, as both immunofluorescence staining and TEM revealed that an intact manchette was still present in the cKO mice, indicating that IFT172 is not a structural component responsible for manchette formation. However, the manchette appeared to be longer when Ift172 was disrupted. Thus, IFT172 might be a key protein that modulates manchette function and plays a role in manchette development. Besides cargo transport, other proposed manchette functions are for shaping sperm heads (Kierszenbaum 2002). Different sperm head shapes were discovered in the Ift172 cKO mice. The abnormal head formation might be caused by manchette dysfunction due to the disruption of Ift 172 . However, the Ift172 gene was not completely depleted, and individual germ cells might express different amounts of residual IFT172 protein, which could result in the observed variations in germ cell phenotypes. IFT172 does not seem to be essential for acrosome biogenesis. The acrosome morphology looks normal in round spermatids as examined by both TEM and IF studies. The distorted acrosomes in the elongating spermatids might be a secondary effect due to the misshapen heads in the absence of IFT172.

TEM analysis of Ift172-null sperm flagella revealed a missing central apparatus and/or disorganization of the ' $9+2$ ' configuration of microtubules in some axoneme, the key structure required for the regulation of motility in cilia and flagella (Mitchell 2004). The abnormal organization of the axoneme likely leads to the immotility of Ift172-null sperm. However, not all sperm had a bent tail, suggesting that the axoneme might not be as severely disrupted in some cells. The direct role of IFT172 on axoneme formation needs intensive TEM studies in the future through analyzing early step spermatids in the Ift $172 \mathrm{cKO}$ mice. It has been reported that the defects of the core axoneme structure might be secondary to the defects of the accessory structures (Young et al. 2016). It is also possible that the abnormal axoneme discovered in some Ift172-null sperm is caused by disrupted accessory structures in the mutant mice. In addition, since the spermatid centrosome is a nucleation site for the axonemal microtubules and the 
manchette is responsible for sorting a large numbers of structural proteins to the centrosome using the IMT machinery (Manandhar et al. 1998, Kierszenbaum 2002, Kierszenbaum et al. 2002), we speculate that dysfunction of the centrosome in the Ift172-null sperm could result in the missing and disrupted central apparatus of some flagella, in addition to the possible disruption in the accessory structure formation as discussed previously. Indeed, Immunofluorescence staining of $\gamma$-tubulin in germ cells of the Ift172-null mice showed multiple spots in the neck region of the elongating spermatid, which would be indicative of centrosome fragmentation. Even though IFT172 is highly abundant in the manchette, the $130 \mathrm{kDa}$ protein was detected from day 12 after birth, when germ cells begin to enter the meiosis phase. Therefore, IFT172 might play other functions during spermatogenesis, including normal centrosome division and migration, which are currently under investigation in the laboratory.

IFT proteins usually function as adaptors for the transport of essential proteins in cilia and flagella (Prevo et al. 2017). To test the possibility that the abnormal sperm morphology is caused by altered expression of other flagella proteins in the Ift172-null mice, we examined the expression levels of selected IFT subunits, including IFT20, IFT25, IFT27, IFT57, IFT74, IFT81, IFT140, and three structural proteins. Most are components of the IFT-B complex (Lucker et al. 2005). Testicular IFT25 and IFT57 expression levels were significantly reduced in the Ift $172 \mathrm{CKO}$ mice. This is consistent with the previous finding that IFT57 is a binding partner of IFT172 (Taschner et al. 2016). Our laboratory has generated male germ cell-specific Ift20 KO mice and the adult males were completely infertile (Zhang et al. 2016); however, some of Ift 172 adult males were still fertile. Although both conditional KO mice displayed similar abnormal sperm morphology and ultrastructure, some Ift20-null germ cells retained redundant cytoplasm, which was not detected in the Ift172-null germ cells. In addition, it is interesting to find that disruption of Ift 172 resulted in reduced expression of AKAP4, a scaffold protein required for formation of the fibrous sheath (Miki et al. 2002). Fibrous sheath mediates diverse signaling/ metabolic pathways important for sperm production and function (Eddy et al. 2003). However, fibrous sheath structure seemed to be normal in the mutant mice. The remaining AKAP4 might be sufficient to maintain normal fibrous sheath assembly. Given that the fibrous sheath is only present in the sperm flagellum but not in other cilia or flagella, it is likely that IFT172 has a unique function in regulating spermiogenesis that is different from the IFT20. IFT20 seems to play a more important role in core axoneme assembly in addition to being involved in the removal of excess cytoplasmic components (Zhang et al. 2016).

IFT25 and IFT27 are two other IFT proteins essential for spermiogenesis and sperm function (Liu et al. 2017,
Zhang et al. 2017). Besides bent tails, sperm from the two respective cKO mice had no motility or reduced motility, round heads, short tails, and abnormal thickness of sperm tails in some areas. Swollen tail tips in some sperm were also discovered in the Ift 25 and lft $27 \mathrm{cKO}$ mice (Liu et al. 2017, Zhang et al. 2017). However, these abnormalities were not found in the Ift172 cKO mice, suggesting that IFT172 is less important in sperm function. Reduced IFT25 and IFT57 levels in the Ift172 cKO mice suggest that IFT172 modulates some IFT proteins in male germ cells. It is not yet known if the reduction is functional to the phenotype described here. There are a total of 22 IFT proteins identified, and it is not known if other IFT proteins are affected when Ift172 is disrupted. This will largely be dependent on the availability of specific antibodies. Recent studies demonstrated that IFT172 is a membrane-interacting protein with the ability to remodel large membranes into small vesicles. IFT172 adopts two different conformations that can be manipulated by lipids. The association of IFT172 with membranes is mutually exclusive with IFT57, implicating multiple functions for IFT172 within IFT (Wang et al. 2018).

In summary, the present study demonstrates that mouse Ift172 gene translates two major proteins, the full-length IFT172, which might be expressed in the somatic cells of the testis, and a 130 kDa IFT172, which is only present in the germ cells. The germ-cell specific IFT172 is indispensable for the completion of normal spermatogenesis. This protein is abundant in the manchette of elongating spermatids and is believed to mediate delivery of essential proteins for the formation of sperm accessory structure and head shaping. The protein plays a role in spermiogenesis for normal centrosome and axoneme formation. The potential multiple functions of IFT172 and the molecular mechanisms involved in spermiogenesis require further investigation.

\section{Supplementary materials}

This is linked to the online version of the paper at https://doi. org/10.1530/REP-17-0789.

\section{Declaration of interest}

The authors declare that there is no conflict of interest that could be perceived as prejudicing the impartiality of the research reported.

\section{Funding}

This research was supported by NIH grant HD076257, HD090306 (to Z Z), start up fund of Wayne State University, Natural Science Foundation of China (81671514), youth talents program of Hubei provincial department of education (Q20181105), and excellent young and middle-aged scientific research and innovation team fund (2018TDZ03). Confocal 
microscopy and S.E.M. were performed in the VCU Microscopy Facility of Virginia Commonwealth University (5P30NS047463) and Microscopy Core at Wayne State University.

\section{Author contribution statement}

S Z, Y L, and Q H performed the experiments and wrote the manuscript. S Y, H L, L S, Y T Y, W L, and J Z participated in experimental work and data analysis. $\mathrm{L} Z$ and $\mathrm{R} A \mathrm{H}$ contributed to the conception of study design and revised the manuscript. $\mathrm{Z} Z$ designed the study, interpreted the data, and revised the manuscript.

\section{Acknowledgments}

We thank Dr Scott C Henderson and Judy C Williamson for their assistance with the electronic microscopy in the Microscopy Core Facility of Virginia Commonwealth University and Dr Alicia Withrow for using the electronic microscope in the Center for Advanced Microscopy of Michigan State University.

\section{References}

Adams GM, Huang B \& Luck DJ 1982 Temperature-sensitive, assemblydefective flagella mutants of Chlamydomonas reinhardtii. Genetics $\mathbf{1 0 0}$ 579-586.

Aldahmesh MA, Li Y, Alhashem A, Anazi S, Alkuraya H, Hashem M, Awaji AA, Sogaty S, Alkharashi A, Alzahrani S et al. 2014 IFT27, encoding a small GTPase component of IFT particles, is mutated in a consanguineous family with Bardet-Biedl syndrome. Human Molecular Genetics 23 3307-3315. (https://doi.org/10.1093/hmg/ddu044)

Beales PL, Bland E, Tobin JL, Bacchelli C, Tuysuz B, Hill J, Rix S, Pearson CG, Kai M, Hartley J et al. 2007 IFT80, which encodes a conserved intraflagellar transport protein, is mutated in Jeune asphyxiating thoracic dystrophy. Nature Genetics 39 727-729. (https://doi.org/10.1038/ ng2038)

Bell LR, Stone S, Yochem J, Shaw JE \& Herman RK 2006 The molecular identities of the Caenorhabditis elegans intraflagellar transport genes dyf6, daf-10 and osm-1. Genetics 173 1275-1286. (https://doi.org/10.1534/ genetics.106.056721)

Bellve AR, Cavicchia JC, Millette CF, O'Brien DA, Bhatnagar YM \& Dym M 1977 Spermatogenic cells of the prepuberal mouse. Isolation and morphological characterization. Journal of Cell Biology 74 68-85. (https://doi.org/10.1083/jcb.74.1.68)

Burnett JB, Lupu FI \& Eggenschwiler JT 2017 Proper ciliary assembly is critical for restricting Hedgehog signaling during early eye development in mice. Developmental Biology 430 32-40. (https://doi.org/10.1016/j. ydbio.2017.07.012)

Carvalho-Santos Z, Azimzadeh J, Pereira-Leal JB \& Bettencourt-Dias M 2011 Evolution: tracing the origins of centrioles, cilia, and flagella. Journal of Cell Biology 194 165-175. (https://doi.org/10.1083/jcb.201011152)

Cole DG, Diener DR, Himelblau AL, Beech PL, Fuster JC \& Rosenbaum JL 1998 Chlamydomonas kinesin-II-dependent intraflagellar transport (IFT): IFT particles contain proteins required for ciliary assembly in Caenorhabditis elegans sensory neurons. Journal of Cell Biology 141 993-1008. (https://doi.org/10.1083/jcb.141.4.993)

Donkor FF, Monnich M, Czirr E, Hollemann T \& Hoyer-Fender S 2004 Outer dense fibre protein 2 (ODF2) is a self-interacting centrosomal protein with affinity for microtubules. Journal of Cell Science $\mathbf{1 1 7}$ 4643-4651. (https://doi.org/10.1242/jcs.01303)

Eddy EM, Toshimori K \& O'Brien DA 2003 Fibrous sheath of mammalian spermatozoa. Microscopy Research and Technique 61 103-115. (https:// doi.org/10.1002/jemt.10320)

Gorivodsky $M$, Mukhopadhyay $M$, Wilsch-Braeuninger $M$, Phillips $M$, Teufel A, Kim C, Malik N, Huttner W \& Westphal H 2009 Intraflagellar transport protein 172 is essential for primary cilia formation and plays

Reproduction (2020) 159 409-421 a vital role in patterning the mammalian brain. Developmental Biology 325 24-32. (https://doi.org/10.1016/j.ydbio.2008.09.019)

Gross JM, Perkins BD, Amsterdam A, Egana A, Darland T, Matsui JI, Sciascia S, Hopkins N \& Dowling JE 2005 Identification of zebrafish insertional mutants with defects in visual system development and function. Genetics 170 245-261. (https://doi.org/10.1534/genetics.104.039727)

Gupta PR, Pendse N, Greenwald SH, Leon M, Liu Q, Pierce EA \& Bujakowska KM 2018 Ift172 conditional knock-out mice exhibit rapid retinal degeneration and protein trafficking defects. Human Molecular Genetics 27 2012-2024. (https://doi.org/10.1093/hmg/ddy109)

Halbritter J, Bizet AA, Schmidts M, Porath JD, Braun DA, Gee HY, McInerney-Leo AM, Krug P, Filhol E, Davis EE et al. 2013 Defects in the IFT-B component IFT172 cause Jeune and Mainzer-Saldino syndromes in humans. American Journal of Human Genetics 93 915-925. (https://doi. org/10.1016/j.ajhg.2013.09.012)

Hermo L, Pelletier RM, Cyr DG \& Smith CE 2010 Surfing the wave, cycle, life history, and genes/proteins expressed by testicular germ cells. Part 2: changes in spermatid organelles associated with development of spermatozoa. Microscopy Research and Technique 73 279-319. (https:// doi.org/10.1002/jemt.20787)

Howard PW \& Maurer RA 2000 Identification of a conserved protein that interacts with specific LIM homeodomain transcription factors. Journal of Biological Chemistry 275 13336-13342. (https://doi.org/10.1074/ jbc.275.18.13336)

Howard PW, Howard TL \& Maurer RA 2010 Generation of mice with a conditional allele for Ift172. Transgenic Research 19 121-126. (https:// doi.org/10.1007/s11248-009-9292-x)

Huangfu D, Liu A, Rakeman AS, Murcia NS, Niswander L \& Anderson KV 2003 Hedgehog signalling in the mouse requires intraflagellar transport proteins. Nature 426 83-87. (https://doi.org/10.1038/nature02061)

Iomini C, Babaev-Khaimov V, Sassaroli M \& Piperno G 2001 Protein particles in Chlamydomonas flagella undergo a transport cycle consisting of four phases. Journal of Cell Biology 153 13-24. (https://doi. org/10.1083/jcb.153.1.13)

Ishikawa H \& Marshall WF 2011 Ciliogenesis: building the cell's antenna. Nature Reviews: Molecular Cell Biology 12 222-234. (https://doi. org/10.1038/nrm3085)

Keady BT, Le YZ \& Pazour GJ 2011 IFT20 is required for opsin trafficking and photoreceptor outer segment development. Molecular Biology of the Cell 22 921-930. (https://doi.org/10.1091/mbc.E10-09-0792)

Kierszenbaum AL 2002 Intramanchette transport (IMT): managing the making of the spermatid head, centrosome, and tail. Molecular Reproduction and Development 63 1-4. (https://doi.org/10.1002/ mrd.10179)

Kierszenbaum AL, Gil M, Rivkin E \& Tres LL 2002 Ran, a GTP-binding protein involved in nucleocytoplasmic transport and microtubule nucleation, relocates from the manchette to the centrosome region during rat spermiogenesis. Molecular Reproduction and Development 63 131-140. (https://doi.org/10.1002/mrd.10164)

Kozminski KG, Johnson KA, Forscher P \& Rosenbaum JL 1993 A motility in the eukaryotic flagellum unrelated to flagellar beating. PNAS 90 5519-5523. (https://doi.org/10.1073/pnas.90.12.5519)

Lehti MS \& Sironen A 2016 Formation and function of the manchette and flagellum during spermatogenesis. Reproduction 151 R43-R54. (https:// doi.org/10.1530/REP-15-0310)

Liu H, Li W, Zhang Y, Zhang Z, Shang X, Zhang L, Zhang S, Li Y, Somoza AV, Delpi B et al. 2017 IFT25, an intraflagellar transporter protein dispensable for ciliogenesis in somatic cells, is essential for sperm flagella formation. Biology of Reproduction 96 993-1006. (https:// doi.org/10.1093/biolre/iox029)

Lucas-Herald AK, Kinning E, lida A, Wang Z, Miyake N, Ikegawa S, McNeilly J \& Ahmed SF 2015 A case of functional growth hormone deficiency and early growth retardation in a child with IFT172 mutations. Journal of Clinical Endocrinology and Metabolism 100 1221-1224. (https://doi.org/10.1210/jc.2014-3852)

Lucker BF, Behal RH, Qin H, Siron LC, Taggart WD, Rosenbaum JL \& Cole DG 2005 Characterization of the intraflagellar transport complex B core: direct interaction of the IFT81 and IFT74/72 subunits. Journal of Biological Chemistry 280 27688-27696. (https://doi.org/10.1074/jbc. M505062200)

Manandhar G, Sutovsky P, Joshi HC, Stearns T \& Schatten G 1998 Centrosome reduction during mouse spermiogenesis. Developmental Biology 203 424-434. (https://doi.org/10.1006/dbio.1998.8947) 
McClintock TS, Glasser CE, Bose SC \& Bergman DA 2008 Tissue expression patterns identify mouse cilia genes. Physiological Genomics 32 198-206. (https://doi.org/10.1152/physiolgenomics.00128.2007)

Meistrich ML, Trostle-Weige PK \& Russell LD 1990 Abnormal manchette development in spermatids of azh/azh mutant mice. American Journal of Anatomy 188 74-86. (https://doi.org/10.1002/aja.1001880109)

Miki K, Willis WD, Brown PR, Goulding EH, Fulcher KD \& Eddy EM 2002 Targeted disruption of the Akap4 gene causes defects in sperm flagellum and motility. Developmental Biology 248 331-342. (https:// doi.org/10.1006/dbio.2002.0728)

Mitchell DR 2004 Speculations on the evolution of 9+2 organelles and the role of central pair microtubules. Biology of the Cell 96 691-696. (https://doi.org/10.1016/j.biolcel.2004.07.004)

Pazour GJ, Dickert BL \& Witman GB 1999 The DHC1b (DHC2) isoform of cytoplasmic dynein is required for flagellar assembly. Journal of Cell Biology 144 473-481. (https://doi.org/10.1083/jcb.144.3.473)

Pedersen LB, Miller MS, Geimer S, Leitch JM, Rosenbaum JL \& Cole DG 2005 Chlamydomonas IFT172 is encoded by FLA11, interacts with CrEB1, and regulates IFT at the flagellar tip. Current Biology 15 262-266. (https://doi.org/10.1016/j.cub.2005.01.037)

Pedersen LB, Geimer S \& Rosenbaum JL 2006 Dissecting the molecular mechanisms of intraflagellar transport in chlamydomonas. Current Biology 16 450-459. (https://doi.org/10.1016/j.cub.2006.02.020)

Perkins LA, Hedgecock EM, Thomson JN \& Culotti JG 1986 Mutant sensory cilia in the nematode Caenorhabditis elegans. Developmental Biology 117 456-487. (https://doi.org/10.1016/0012-1606(86)90314-3)

Perrault I, Halbritter J, Porath JD, Gerard X, Braun DA, Gee HY, Fathy HM, Saunier S, Cormier-Daire V, Thomas S et al. 2015 IFT81, encoding an IFT-B core protein, as a very rare cause of a ciliopathy phenotype. Journal of Medical Genetics 52 657-665. (https://doi.org/10.1136/ jmedgenet-2014-102838)

Piperno G \& Mead K 1997 Transport of a novel complex in the cytoplasmic matrix of Chlamydomonas flagella. PNAS 94 4457-4462. (https://doi. org/10.1073/pnas.94.9.4457)

Porter ME, Bower R, Knott JA, Byrd P \& Dentler W 1999 Cytoplasmic dynein heavy chain $1 \mathrm{~b}$ is required for flagellar assembly in Chlamydomonas. Molecular Biology of the Cell 10 693-712. (https://doi.org/10.1091/ mbc.10.3.693)

Prevo B, Scholey JM \& Peterman EJG 2017 Intraflagellar transport: mechanisms of motor action, cooperation, and cargo delivery. FEBS Journal 284 2905-2931. (https://doi.org/10.1111/febs.14068)

Sadate-Ngatchou PI, Payne CJ, Dearth AT \& Braun RE 2008 Cre recombinase activity specific to postnatal, premeiotic male germ cells in transgenic mice. Genesis 46 738-742. (https://doi.org/10.1002/dvg.20437)

Schaefer E, Stoetzel C, Scheidecker S, Geoffroy V, Prasad MK, Redin C, Missotte I, Lacombe D, Mandel JL, Muller J et al. 2016 Identification of a novel mutation confirms the implication of IFT172 (BBS20) in BardetBiedl syndrome. Journal of Human Genetics 61 447-450. (https://doi. org/10.1038/jhg.2015.162)

Scholey JM 2013 Kinesin-2: a family of heterotrimeric and homodimeric motors with diverse intracellular transport functions. Annual Review of Cell and Developmental Biology 29 443-469. (https://doi.org/10.1146/ annurev-cellbio-101512-122335)

Shi L, Zhou T, Huang Q, Zhang S, Li W, Zhang L, Hess RA, Pazour GJ \& Zhang Z 2019 Intraflagellar transport protein 74 is essential for spermatogenesis and male fertility in mice. Biology of Reproduction 101 188-199. (https://doi.org/10.1093/biolre/ioz071)

Silva C, Wood JR, Salvador L, Zhang Z, Kostetskii I, Williams CJ \& Strauss 3rd JF 2009 Expression profile of male germ cell-associated genes in mouse embryonic stem cell cultures treated with all-trans retinoic acid and testosterone. Molecular Reproduction and Development 76 11-21. (https://doi.org/10.1002/mrd.20925)
Sukumaran S \& Perkins BD 2009 Early defects in photoreceptor outer segment morphogenesis in zebrafish ift57, ift88 and ift172 Intraflagellar Transport mutants. Vision Research 49 479-489. (https://doi. org/10.1016/j.visres.2008.12.009)

Sun Z, Amsterdam A, Pazour GJ, Cole DG, Miller MS \& Hopkins N 2004 A genetic screen in zebrafish identifies cilia genes as a principal cause of cystic kidney. Development 131 4085-4093. (https://doi.org/10.1242/ dev.01240)

Taschner M, Weber K, Mourao A, Vetter M, Awasthi M, Stiegler M, Bhogaraju S \& Lorentzen E 2016 Intraflagellar transport proteins 172, 80, 57, 54, 38, and 20 form a stable tubulin-binding IFT-B2 complex. EMBO Journal 35 773-790. (https://doi.org/10.15252/embj.201593164)

Tsao CC \& Gorovsky MA 2008 Different effects of Tetrahymena IFT172 domains on anterograde and retrograde intraflagellar transport. Molecular Biology of the Cell 19 1450-1461. (https://doi.org/10.1091/ mbc.e07-05-0403)

Tsuneoka M, Nishimune Y, Ohta K, Teye K, Tanaka H, Soejima M, lida H, Inokuchi T, Kimura H \& Koda Y 2006 Expression of Mina53, a product of a Myc target gene in mouse testis. International Journal of Andrology 29 323-330. (https://doi.org/10.1111/j.1365-2605.2005.00572.x)

Wang Q, Taschner M, Ganzinger KA, Kelley C, Villasenor A, Heymann M, Schwille P, Lorentzen E \& Mizuno N 2018 Membrane association and remodeling by intraflagellar transport protein IFT172. Nature Communications 9 4684. (https://doi.org/10.1038/s41467-01807037-9)

Waters AM \& Beales PL 2011 Ciliopathies: an expanding disease spectrum. Pediatric Nephrology 26 1039-1056. (https://doi.org/10.1007/s00467010-1731-7)

Young SAM, Miyata H, Satouh Y, Aitken RJ, Baker MA \& Ikawa M 2016 CABYR is essential for fibrous sheath integrity and progressive motility in mouse spermatozoa. Journal of Cell Science 129 4379-4387. (https:// doi.org/10.1242/jcs.193151)

Zhang Z, Kostetskii I, Tang W, Haig-Ladewig L, Sapiro R, Wei Z, Patel AM, Bennett J, Gerton GL, Moss SB et al. 2006 Deficiency of SPAG16L causes male infertility associated with impaired sperm motility. Biology of Reproduction 74 751-759. (https://doi.org/10.1095/ biolreprod.105.049254)

Zhang Z, Li W, Zhang Y, Zhang L, Teves ME, Liu H, Strauss 3rd JF, Pazour GJ, Foster JA, Hess RA et al. 2016 Intraflagellar transport protein IFT20 is essential for male fertility and spermiogenesis in mice. Molecular Biology of the Cell 27 3705-3716. (https://doi.org/10.1091/ mbc.E16-05-0318)

Zhang Y, Liu H, Li W, Zhang Z, Shang X, Zhang D, Li Y, Zhang S, Liu J, Hess RA et al. 2017 Intraflagellar transporter protein (IFT27), an IFT25 binding partner, is essential for male fertility and spermiogenesis in mice. Developmental Biology 432 125-139. (https://doi.org/10.1016/j. ydbio.2017.09.023)

Zhang Y, Liu H, Li W, Zhang Z, Zhang S, Teves ME, Stevens C, Foster JA, Campbell GE, Windle JJ et al. 2018 Intraflagellar transporter protein 140 (IFT140), a component of IFT-A complex, is essential for male fertility and spermiogenesis in mice. Cytoskeleton 75 70-84. (https://doi. org/10.1002/cm.21427)

Received 31 December 2017

First decision 15 February 2018

Revised manuscript received 13 December 2019

Accepted 20 January 2020 